\title{
Circulating Angiogenic microRNA-27b and Thrombospondin-1 (TSP-1) Level in Patients with Diabetic Retinopathy \\ SamiaSouka Moustafa ${ }^{1}$, MaisaNour El-Din Shawkey ${ }^{1}$, Aida Ahmed Abd Elhameed, Mohamed Maher EL Hefny ${ }^{2}$, RaghdaAbd-ElsalamNagaty Hanady ${ }^{1 *}$
}

${ }^{1}$ Department of Chemical Pathology, Faculty of Medicine, Al-Azhar University, ${ }^{2}$ Department of Ophthalmology, Research Institute of Ophthalmology-Ministry of Scientific Research

* Corresponding author:RaghdaAbd-ElsalamNagatyHanady, Mobile: (+20)01008141591,

E-mail:tantawy_wael@yahoo.com

\section{ABSTRACT}

Background: Diabetes mellitus (DM) is a chronic disease characterized by insulin deficiency or its peripheral resistance resulting in hyperglycemia and non-enzymatic glycation of protein. The chronic hyperglycemia of diabetes is associated with long-term damage, dysfunction, and failure of different organs, especially the eyes, kidneys, nerves, heart, and blood vessels. MicroRNAs (miRNAs) are a class of highly conserved 19-25 nucleotide noncoding RNAs that regulate gene expression.

Objective:This study aimed to assess plasma miR-27b expression in diabetic retinopathy patients as an early diagnostic parameter in both proliferative and non-proliferative and to assess the correlation between plasma levels of miR-27b with the clinico-pathological parameters of diabetic patients as well as determination of the level of thrombospondin-1 (TSP1).

Patients and Methods: This study was conducted on 60 diabetic retinopathy Egyptian patients that were recruited from the Research Institute of Ophthalmology - RIO (Medical Retina Clinics) during their routine screening for diabetic retinopathy.

Results: Micro RNA 27b shows a highly significant difference (increase) among PDR compared to non-PDR \& control groups (P value: 0.001) and shows a moderately significant increase in expression in PDR group compared to control group ( $\mathrm{P}$ value: 0.01 ). This significant increase in microRNA between PDR group and control group has the ability of being a non-invasive biomarker for diagnosis of PDR versus control group, as miRNA-27b expression showed AUC $=0.889$ with (95\% CI $0.744-1.000)$. The best cut-off point of miRNA-27b is 1.95 with $88.9 \%$ sensitivity \& $100 \%$ specificity and the $\mathrm{p}$ value $<0.001$ (highly significant).

Conclusion: TSP-1 can act as a predictor for transformation of non-retinopathy stage to PDR stage. miRNA-27b has the ability to differentiate between the PDR and control group and could be considered a non invasive biomarker. Keywords: Diabetes mellitus, microRNA-27b, Thrombospondin-1, Diabetic retinopathy.

\section{INTRODUCTION}

Diabetes mellitus (DM) is a chronic disease characterized by insulin deficiency or its peripheral resistance resulting in hyperglycemia and nonenzymatic glycation of protein ${ }^{(\mathbf{1})}$. The chronic hyperglycemia of diabetes is associated with longterm damage, dysfunction, and failure of different organs, especially the eyes, kidneys, nerves, heart and blood vessels. Several pathogenic processes are involved in the development of diabetes. These range from autoimmune destruction of the pancreatic $\beta$ cells with consequent insulin deficiency to abnormalities that result in resistance to insulin action. The basis of the abnormalities in carbohydrate, fat, and protein metabolism in diabetes is deficient action of insulin on target tissues ${ }^{(2)}$.

Diabetic retinopathy (DR) is the most common complication of diabetes mellitus (DM). It has long been recognized as a micro vascular disease. The diagnosis of DR relies on the detection of micro vascular lesions. The treatment of DR remains challenging. The advent of anti-vascular endothelial growth factor (anti-VEGF) therapy demonstrated remarkable clinical benefits in DR patients. However, the majority of patients failed to achieve clinically significant visual improvement ${ }^{(3)}$.

Therefore, there is an urgent need for the development of new treatments. Laboratory and clinical evidence showed that in addition to microvascular changes, inflammation and retinal neurodegeneration might contribute to diabetic retinal damage in the early stages of DR. Further investigation of the underlying molecular mechanisms may provide targets for the development of new early interventions ${ }^{(3)}$.

In the last decade, miRNAs have received substantial attention as potential players of diabetes microvascular complications, affecting the kidney, the retina, and the peripheral neurons. Compelling evidence indicates that abnormally expressed miRNAs have pivotal roles in key pathogenic processes of microvascular complications, such as fibrosis, apoptosis, inflammation and angiogenesis. Moreover, clinical research into innovative both diagnostic and prognostic tools suggests circulating miRNAs as possible novel noninvasive markers of diabetes microvascular complications ${ }^{(4)}$.

Zampetaki and his colleagues ${ }^{(5)}$ had identified miR-27b and miR-320a as being significantly and independently associated with high DR risk. Complementing this analysis, they also elucidated the potential mechanism using cultured human endothelial cells and identified antiangiogenic thrombospondin-1 (TSP-1) as a common target of these two miRNAs.

\section{AIM OF THE WORK}


1. Assessment of plasma miR-27b expression in diabetic retinopathy patients as an early diagnostic parameter in both proliferative and non-proliferative DR.

2. Assessment of the correlation between plasma levels of miR-27b with the clinico-pathological parameters of diabetic patients and determination of the level of thrombospondin-1 (TSP1).

\section{PATIENTS AND METHODS}

This study was conducted on 60 Egyptian adults who were divided into three groups:

- Group I: 20 proliferative diabetic retinopathy (DR) patients.

- Group II: 20 non-proliferative DR patients.

- Group III: 20 diabetic, age-matched patients without evident diabetic retinopathy.

All diabetic retinopathy \& diabetic patients were recruited from the Research Institute of Ophthalmology - RIO (Medical Retina Clinics) during their routine screening for diabetic retinopathy.

Data regarding patients' gender, age, weight, retinal and ophthalmologic investigations (Fundus Fluorescein angiography (FFA) and Optical coherence tomography $(O C T)\}$ were obtained from patients' medical records at the Ophthalmology Department of Research Institute of Ophthalmology (RIO).

\section{Exclusion criteria:}

Patients having any of the following conditions were excluded from the study:

1. Eye conditions that precluded capture of gradable retinal photographs (i.e., open-angle glaucoma, dense cataract obscuring retinal view).

2. Other evident micro or macro-vascular complications which may affect the level of $27 \mathrm{~b}$ such as coronary artery disease.

3. Drugs, which may interfere with expression of miR-27b, such as estrogen receptor (ER) antagonists (Tamoxifen), which is used in breast cancer

\section{Laboratory investigations:}

$10 \mathrm{~cm}$ of blood was withdrawn from each patient on 2 separate sittings and distributed as follows:

- $2 \mathrm{~cm}$ in yellow capped tube for measurement of serum cre ,totalchol and trig.

- $2 \mathrm{~cm}$ in Edta tube for measurement of micro RNA.

- $2 \mathrm{~cm}$ in Edta tube for measurement of HBA1C

- $2 \mathrm{~cm}$ in yellow capped tube for measurement of serum thrombospondin-1

- $2 \mathrm{~cm}$ in grey capped fluoride tube for measurement of FBS

1. Routine Biochemical Studies:

- Serum creatinine, total cholesterol, triglycerides\& fasting blood sugar (FBS)
- The total cholesterol and triglycerides sample was collected after 10-12 hours fasting while the fasting blood glucose after 8-10 hours fasting in different setting.

- Blood sample was collected on vacuum serumseparating gel tube (yellow-capped), for total cholesterol, triglycerides and creatinine then centrifuged at $3000 \mathrm{rpm}$ for 15 minutes.

- Serum creatinine, total cholesterol, and triglycerides assays were performed on the automated Erba XL SysPack 300 analyzer after passing the 2-levels internal quality control. The serum total cholesterol (enzymatic single step method by cholesterol esterase enzyme), while triglycerides (enzymatic hydrolysis by lipase to glycerol and fatty acids) were assayed using series of enzymatic reactions in a Trinder type color reaction catalyzed by peroxidase done according to the manufacturer's instructions and creatinine was measured by jaffe reaction.

- FBS was measured in blood samples collected in vacuum tubes containing sodium fluoride (greycapped). Samples were centrifuged at $3000 \mathrm{rpm}$ for 15 minutes and analyzed using the automated Erba XLSYS Pack 300 instrument after passing the 2-levels internal quality control. The FBS test was performed using Trinder's method.

\section{HbA1C:}

$>$ Blood samples were collected on vacuum blood collection tubes containing K+ EDTA (blood collected till the mark on the tube), then RBCs lysis was performed by hemolysing solution (provided with the assay kit)

$>$ The processed blood samples were then analyzed by the automated Erba XL SysPack 300 instrument after passing the 2-levels internal quality control.

$>$ The method used is direct assay of HA1C via particle-enhanced immunoturbidimetric assay.

\section{Urine albumin:}

Fresh random urine samples were collected from all cases for albumin detection.

$>$ Albumin detection through chemical analysis which was performed by Urinalysis Reagent Strips which are particularly sensitive to albumin. when the dry reagent come in contact with urine albumin,the reagent is activated and chemical reaction occurs in the form of specific color change which is observed visually and compared with a special color chart (positive results range from green means trace less than $30 \mathrm{mg} / \mathrm{dl}$ to light green means $30 \mathrm{mg} / \mathrm{dl}$, dark green +2 means $100 \mathrm{mg} / \mathrm{dl}$ and finally blue green +3 means $500 \mathrm{mg} / \mathrm{dl}$ )

N.BAll the kits were supplied from Erba diagnostics a member of ERBA Mannheim group from Gama Trade Company.

\section{Specific laboratory tests:}

a- Plasma for detection of microRNA 27b. 
b- Serum for detection of

Thrombospondin-1.

a) Analysis of the expression level of mature miRNA (miRNA-27b):

$>$ Two milliliters of venous blood were collected on sterile vaccutainer tube containing $\mathrm{K}_{2}$ EDTA (Lavander-capped) and centrifuged at $3400 \mathrm{rpm}$ for $15 \mathrm{~min}$ at $4^{\circ} \mathrm{c}$ (cooling centrifuge).

$>$ Supernatant plasma was transferred to sterile, properly identified Eppendorf tube. These samples were stored at $-20^{\circ} \mathrm{C}$ until RNA extraction.

$>$ All procedures were carried out under sterile conditions and all samples and kits were opened in laminar airflow.

- The miRNA assay steps were done as following:

I. RNA Extraction.

II. Reverse transcription and cDNA formation.

III. Detection of expression.

Ethical approval:

The study was approved by the Ethics Board of Al-Azhar University and an informed written consent was taken from each participant in the study.

\section{Statistical Methods}

Data were analyzed using SPSS win (Statistical Package for Social Science) version 21. Numerical data was described as mean and standard deviation (SD), while qualitative data were described as frequency and percentage. Comparison between groups with respect to numerical variables was done using either parametric t-test or nonparametric analogue Mann Whiteny as appropriate. Qualitative data were compared using Chi-square test or Fisher's exact as appropriate. $\mathrm{P}$ value less than or equal to 0.05 is considered statistically significant. All tests were 2tailed.

\section{RESULTS}

Table (1): Demographic Data

\begin{tabular}{|c|c|c|c|c|c|}
\hline \multicolumn{2}{|c|}{$\begin{array}{c}\text { Demographic } \\
\text { data }\end{array}$} & $\begin{array}{c}\text { PD } \\
\text { R }\end{array}$ & $\begin{array}{c}\text { Non- } \\
\text { PDR }\end{array}$ & $\begin{array}{c}\text { Cont } \\
\text { rol }\end{array}$ & $\begin{array}{c}\text { P } \\
\text { value }\end{array}$ \\
\hline Age & Mean & 54.5 & $58.6 \pm$ & $59.9 \pm$ & 0.104 \\
& \pm SD & \pm 8.5 & 8.9 & 6.3 & \\
\hline Gender & Male & 14 & 10 & 6 & 0.009 \\
& & $(46.7 \%)$ & $(33.3 \%)$ & $(20 \%)$ & \\
\cline { 2 - 5 } & Female & 4 & 14 & 14 & \\
\hline Weight & Mean & $(12.5 \%)$ & $(43.8 \%)$ & $(43.8 \%)$ & \\
& \pm SD & \pm & $83.9 \pm$ & $86.4 \pm$ & 0.372 \\
& & 12.3 & 12.3 & \\
\hline
\end{tabular}

Age (years) and weight (Kgs) are represented as

Mean $\pm S D$ and sex is represented as number and percent.

Statistical comparison of demographic data showed no significant difference among PDR, non-
PDR \& control groups regarding degree of mean value of age and weight. Whereas, there was a moderately significant difference in gender among PDR, non-PDR \& control groups (Table 1).

Table (2): Statistical comparison of laboratory data regarding miRNA-27b expression and thrombospondin-1 (TSP-1) level among PDR, nonPDR, \& control groups

\begin{tabular}{|l|c|c|c|c|c|}
\hline \multicolumn{2}{|c|}{$\begin{array}{c}\text { Lab } \\
\text { parameter }\end{array}$} & $\begin{array}{c}\text { PDR } \\
(\mathbf{n = 2 0})\end{array}$ & $\begin{array}{c}\text { Non- } \\
\text { PDR } \\
(\mathbf{n}=20)\end{array}$ & $\begin{array}{c}\text { Control } \\
(\mathbf{n}=\mathbf{2 0})\end{array}$ & $\begin{array}{c}\text { P- } \\
\text { value }\end{array}$ \\
\hline $\mathrm{miRN}$ & $\mathrm{RQ}$ & $86 \pm 102$ & $41.4 \pm$ & $1.0 \pm$ & 0.001 \\
$\mathrm{~A}-27 \mathrm{~b}$ & & & 59.2 & 0.0 & \\
\hline $\mathrm{TSP}-1$ & $\mathrm{pg} /$ & $1349.2 \pm 7$ & $1659.3 \pm$ & $1994 \pm$ & 0.007 \\
& $\mathrm{ml}$ & 22.5 & 603.4 & 470.1 & \\
\hline
\end{tabular}

miRNA $27 \mathrm{~b}(R Q)$ and $T S P-1(\mathrm{pg} / \mathrm{ml})$ are expressed as mean \pm standard deviation.

$P$-value $>0.05 \rightarrow$ non-significant, $P<0.05 \rightarrow$ significant, $P<0.01 \rightarrow$ moderately significant, $P<0.001 \rightarrow$ highly significant.

Table (3): Statistical comparison of laboratory data regarding miRNA-27b expression and thrombospondin-1 (TSP-1) level between PDR \& control groups

\begin{tabular}{|c|c|c|c|c|}
\hline \multicolumn{2}{|c|}{$\begin{array}{c}\text { Lab } \\
\text { parameter }\end{array}$} & $\begin{array}{c}\text { PDR } \\
(\mathbf{n}=20)\end{array}$ & $\begin{array}{r}\text { Control } \\
(\mathbf{n}=20)\end{array}$ & $\begin{array}{l}\text { P- } \\
\text { val }\end{array}$ \\
\hline $\begin{array}{l}\text { miRN } \\
\text { A-27b }\end{array}$ & RQ & $86 \pm 102$ & $1.0 \pm 0.0$ & $\begin{array}{c}0.0 \\
1\end{array}$ \\
\hline TSP-1 & $\begin{array}{l}\mathrm{pg} / \\
\mathrm{ml}\end{array}$ & $\begin{array}{c}1349.2 \pm 72 \\
2.5 \\
\end{array}$ & $\begin{array}{c}1994 \pm 47 \\
0.1 \\
\end{array}$ & 0.005 \\
\hline
\end{tabular}

miRNA 27b (RQ) and TSP-1 (pg/ml) are expressed as mean \pm standard deviation.

$\mathrm{P}$-value $>0.05 \rightarrow$ non-significant, $\mathrm{P}<0.05 \rightarrow$ significant, $\mathrm{P}$ $<0.01 \rightarrow$ moderately significant,

$\mathrm{P}<0.001 \rightarrow$ highly significant.

Statistical comparison of laboratory data regarding mean plasma value of miRNA-27b expression showed a moderately significant increase in expression in PDR group compared to control group (P value: 0.01 ).

Table (4): Statistical comparison of laboratory data regarding miRNA-27b expression and thrombospondin-1 (TSP-1) level between non-PDR \& control groups

\begin{tabular}{|c|l|c|c|c|}
\hline \multicolumn{2}{|c|}{$\begin{array}{c}\text { Lab } \\
\text { parameter }\end{array}$} & $\begin{array}{c}\text { Non-PDR } \\
(\mathbf{n = 2 0})\end{array}$ & $\begin{array}{c}\text { Control } \\
(\mathbf{n = 2 0})\end{array}$ & $\begin{array}{c}\text { P- } \\
\text { value }\end{array}$ \\
\hline $\begin{array}{c}\mathrm{miRN} \\
\mathrm{A} 27 \mathrm{~b}\end{array}$ & $\mathrm{RQ}$ & $41.4 \pm 59.2$ & $1.0 \pm 0.0$ & 0.117 \\
\hline $\mathrm{TSP}-1$ & $\mathrm{pg} / \mathrm{ml}$ & $1659.3 \pm 603.4$ & $1994 \pm 470.1$ & 0.168 \\
\hline
\end{tabular}

miRNA 27b (RQ) and TSP-1 (pg/ml) are expressed as mean \pm standard deviation.P-value $>0.05 \rightarrow$ nonsignificant, $\mathrm{P}<0.05 \rightarrow$ significant, $\mathrm{P}<0.01 \rightarrow$ moderately significant, $\mathrm{P}<0.001 \rightarrow$ highly significant.

Regarding miRNA-27b expression, table (4) showed no significant difference in expression between non-PDR group and control group ( $\mathrm{P}$ value: 0.117). In addition, the statistical comparison of 
laboratory data regarding thrombospondin-1 level in serum showed no significant difference in level between non-PDR group and control group ( $\mathrm{P}$ value: $0.168)$.

Table (5): Statistical comparison of laboratory data regarding miRNA-27b expression and

thrombospondin-1 (TSP-1) level between PDR \& non-PDR groups

\begin{tabular}{|c|c|c|c|c|}
\hline \multicolumn{2}{|c|}{$\begin{array}{c}\text { Lab } \\
\text { parameter }\end{array}$} & $\begin{array}{c}\text { PDR } \\
(\mathbf{n}=20)\end{array}$ & $\begin{array}{c}\text { Non- } \\
\text { PDR } \\
(\mathbf{n}=20)\end{array}$ & $\begin{array}{c}\text { P- } \\
\text { val } \\
\text { ue }\end{array}$ \\
\hline $\mathrm{miR}$ & $\mathrm{RQ}$ & $86 \pm 102$ & $41.4 \pm$ & 0.0 \\
$\mathrm{NA}$ & & & 59.2 & 86 \\
$27 \mathrm{~b}$ & & & & \\
\hline $\begin{array}{c}\text { TSP- } \\
1\end{array}$ & $\mathrm{pg} /$ & $1349.2 \pm 7$ & $1659.3 \pm 6$ & 0.2 \\
$\mathrm{ml}$ & 22.5 & 03.4 & 33 \\
\hline
\end{tabular}

miRNA $27 b(R Q)$ and TSP-1 $(\mathrm{pg} / \mathrm{ml})$ are expressed as mean \pm standard deviation.

$P$-value $>0.05 \rightarrow$ non-significant, $P<0.05 \rightarrow$ significant, $P<0.01 \rightarrow$ moderately significant, $P<0.001 \rightarrow$ highly significant.

Regarding miRNA-27b expression, table (5) showed near significant difference (increase) in expression in PDR group compared to non-PDR group ( $\mathrm{P}$ value: 0.086). While, the statistical comparison of laboratory data regarding thrombospondin-1 level in serum showed no significant difference in level between PDR group and non-PDR group (P value: 0.233).

Table (6): Correlation Analysis between the studied miRNA-27b expression and thrombospondin-1 level in PDR group

\begin{tabular}{|c|c|c|c|}
\hline Parameter & \multicolumn{2}{|c|}{ miRNA 27b } & $\begin{array}{c}\text { Significance } \\
\text { (2-tailed) }\end{array}$ \\
\hline & R & P & \\
\hline TSP-1 & -0.12 & 0.634 & $\begin{array}{c}\text { Not } \\
\text { significant }\end{array}$ \\
\hline
\end{tabular}

\section{$r=$ Pearson correlation, $p=$ significance}

The mean value of miRNA-27b showed no statistically significant correlation with mean level of serum thrombospondin-1 level in the PDR group ( $\mathrm{r}=$ $-0.12, p=0.634)$ as shown in table (6).

Table (7): Correlation Analysis between the studied miRNA-27b expression and thrombospondin-1 level in non-PDR group

\begin{tabular}{|c|c|c|c|}
\hline Parameter & \multicolumn{2}{|c|}{ miRNA 27b } & $\begin{array}{c}\text { Significance } \\
\text { (2-tailed) }\end{array}$ \\
\hline & R & P & \\
\hline TSP-1 & .058 & 0.789 & $\begin{array}{c}\text { Not } \\
\text { significant }\end{array}$ \\
\hline
\end{tabular}

$r=$ Pearson correlation, $p=$ significance

Table (7) showed that the mean value of miRNA-27b showed no statistically significant correlation with mean level of serum thrombospondin-1 level in the non-PDR group $(r=0.058, p=0.789)$.
Table (8): Correlation analysis of the studied miRNA-27b \& TSP-1 with other clinical and laboratory parameters in the PDR group

\begin{tabular}{|c|c|c|c|}
\hline \multicolumn{2}{|l|}{ Parameter } & TSP-1 & $\begin{array}{l}\text { miRNA } \\
\text { 27b RQ }\end{array}$ \\
\hline \multirow{3}{*}{$\begin{array}{l}\text { duration of } \\
\text { DM+ } \\
\text { Treatment }\end{array}$} & $\begin{array}{l}\text { Pearson } \\
\text { Correlation }\end{array}$ & .100 & .031 \\
\hline & $\begin{array}{l}\text { Significance } \\
\text { (2-tailed) }\end{array}$ & .692 & .903 \\
\hline & Number & 18 & 18 \\
\hline \multirow[t]{3}{*}{ Blood sugar } & $\begin{array}{l}\text { Pearson } \\
\text { Correlation }\end{array}$ & .070 & .137 \\
\hline & $\begin{array}{l}\text { Significance } \\
\text { (2-tailed) }\end{array}$ & .783 & .589 \\
\hline & Number & 18 & 18 \\
\hline \multirow[t]{3}{*}{ creatinine } & $\begin{array}{l}\text { Pearson } \\
\text { Correlation }\end{array}$ & -.239 & -.148 \\
\hline & $\begin{array}{l}\text { Significance } \\
\text { (2-tailed) }\end{array}$ & .339 & .557 \\
\hline & Number & 18 & 18 \\
\hline \multirow[t]{3}{*}{ HbA1C } & $\begin{array}{l}\text { Pearson } \\
\text { Correlation }\end{array}$ & -.356 & -.228 \\
\hline & $\begin{array}{l}\text { Significance } \\
\text { (2-tailed) }\end{array}$ & .147 & .363 \\
\hline & Number & 18 & 18 \\
\hline \multirow[t]{3}{*}{$\begin{array}{l}\text { Cholesterol } \\
\text { (total) }\end{array}$} & $\begin{array}{l}\text { Pearson } \\
\text { Correlation }\end{array}$ & .150 & -.240 \\
\hline & $\begin{array}{l}\text { Significance } \\
\text { (2-tailed) }\end{array}$ & .551 & .338 \\
\hline & Number & 18 & 18 \\
\hline \multirow[t]{3}{*}{ triglycerides } & $\begin{array}{l}\text { Pearson } \\
\text { Correlation }\end{array}$ & .023 & -.286 \\
\hline & $\begin{array}{l}\text { Significance } \\
\text { (2-tailed) }\end{array}$ & .928 & .250 \\
\hline & Number & 18 & 18 \\
\hline
\end{tabular}

The statistical analysis of the correlations between serum miRNA-27b \& TSP-1 and other clinical and laboratory parameters in the PDR group showed no statistical significance in any of the correlations done as shown in table (8).

Table (9): Correlation analysis of the studied miRNA27b \& TSP-1 with other clinical and laboratory parameters in thenon-PDR group

\begin{tabular}{|l|l|c|c|}
\hline \multirow{2}{*}{$\begin{array}{l}\text { Parameter } \\
\text { duration of } \\
\text { DM+ } \\
\text { Treatment }\end{array}$} & $\begin{array}{l}\text { Pearson } \\
\text { Correlation }\end{array}$ & -.284 & $\begin{array}{l}\text { miRNA } \\
\text { 27b RQ }\end{array}$ \\
\cline { 2 - 4 } & $\begin{array}{l}\text { Significance (2- } \\
\text { tailed) }\end{array}$ & .179 & .488 \\
\cline { 2 - 4 } & Number & 24 & 24 \\
\hline Blood sugar & $\begin{array}{l}\text { Pearson } \\
\text { Correlation }\end{array}$ & -.241 & -.223 \\
\cline { 2 - 4 } & $\begin{array}{l}\text { Significance (2- } \\
\text { tailed) }\end{array}$ & .258 & .294 \\
\cline { 2 - 4 } & Number & 24 & 24 \\
\hline creatinine & $\begin{array}{l}\text { Pearson } \\
\text { Correlation }\end{array}$ & -.101 & -.269 \\
\hline
\end{tabular}




\begin{tabular}{|l|l|l|l|}
\hline \multirow{7}{*}{} & $\begin{array}{l}\text { Significance (2- } \\
\text { tailed) }\end{array}$ & .638 & .204 \\
\cline { 2 - 4 } & Number & 24 & 24 \\
\hline \multirow{5}{*}{ HbA1C } & $\begin{array}{l}\text { Pearson } \\
\text { Correlation }\end{array}$ & -.078 & .059 \\
\cline { 2 - 4 } & $\begin{array}{l}\text { Significance (2- } \\
\text { tailed) }\end{array}$ & .717 & .784 \\
\cline { 2 - 4 } & Number & 24 & 24 \\
\hline Cholesterol & $\begin{array}{l}\text { Pearson } \\
\text { Correlation }\end{array}$ & .108 & -.150 \\
\cline { 2 - 4 } & $\begin{array}{l}\text { Significance (2- } \\
\text { tailed) }\end{array}$ & .615 & .483 \\
\cline { 2 - 4 } & Number & 24 & 24 \\
\hline \multirow{2}{*}{ triglycerides } & $\begin{array}{l}\text { Pearson } \\
\text { Correlation }\end{array}$ & .218 & .153 \\
\cline { 2 - 4 } & $\begin{array}{l}\text { Significance (2- } \\
\text { tailed) }\end{array}$ & .305 & .475 \\
\cline { 2 - 4 } & Number & 24 & 24 \\
\hline
\end{tabular}

The statistical analysis of the correlations between serum miRNA-27b \& TSP-1 and other clinical and laboratory parameters in the non-PDR group showed no statistical significance in any of the correlations done (Table 9).

\section{The diagnostic validity of miRNA-27b and}

\section{thrombospondin-1 (TSP-1) for PDR versus}

\section{control group}

Diagnostic validity test for miR-27b was done for PDR group versus control group and showed that the area under the curve (AUC) is 0.889 with 95\% Confidence Interval (CI): (0.744-1.0) and the best cut off point of miRNA-27b is (1.95) with sensitivity (88.9\%) and specificity was (100\%). The $\mathrm{P}$ value is highly significant $(<0.001)$.

ROC curve analysis for serum TSP-1 for PDR versus control group showed that the area under the curve (AUC) is 0.242 with $95 \%$ Confidence Interval (CI): (0.085-0.398) and the best cut off point of miRNA-27b is (1.95) with sensitivity $(27.8 \%)$ and specificity was (30\%). The $\mathrm{P}$ value is moderately significant (0.007) as shown in Table (10)

This means that miRNA-27b has the ability to differentiate between the PDR and control group and could be considered a non-invasive biomarker for diagnosis of diabetic retinopathy.

Moreover, TSP-1 can act as a non-invasive predictor for transformation from non-retinopathy stage to PDR stage.

Table (10): The diagnostic validity of miRNA27b\& TSP-1 for PDR versus control groups

\begin{tabular}{|l|l|l|l|l|l|}
\hline \multicolumn{5}{|c|}{ Area Under the Curve } \\
\hline $\begin{array}{l}\text { Test Result } \\
\text { Variable(s) }\end{array}$ & AUC & & P value & & $\begin{array}{l}\text { 95\% Confidence } \\
\text { Interval }\end{array}$ \\
\hline
\end{tabular}

\begin{tabular}{|l|l|l|l|l|l|l|l|}
\hline & & $\begin{array}{l}\text { Cut- } \\
\text { off } \\
\text { point }\end{array}$ & & Sensitivity & Specificity & $\begin{array}{l}\text { Lower } \\
\text { Bound }\end{array}$ & $\begin{array}{l}\text { Upper } \\
\text { Bound }\end{array}$ \\
\hline TPO & 0.242 & 2052 & 0.007 & $27.8 \%$ & $30.0 \%$ & 0.085 & 0.398 \\
\hline $27 b$ RQ & 0.889 & 1.95 & $<0.001$ & $88.9 \%$ & $100.0 \%$ & 0.744 & 1.000 \\
\hline
\end{tabular}

\section{DISCUSSION}

In our study, there was no statistically significant difference in serum mean values of total cholesterol levels and triglyceride values between PDR, non-PDR and control groups with $\mathrm{p}$ value (0.217 and 0.129 respectively). There is an agreement between our study and the study of Klein et al. ${ }^{(7)}$ who found that there was no associations between serum total or high-density lipoprotein (HDL) cholesterol and incident proliferative diabetic retinopathy or macular edema. While, the study done by Agroiya $\boldsymbol{e t} \boldsymbol{a l} .{ }^{(\boldsymbol{6})}$ disagrees with our results where they showed that there was statistically significant positive correlation between severity of DR and triglycerides with $\mathrm{P}$ value (0.001).

In our study, we found no statistically significant difference in $\mathrm{HbA1C}$ mean levels (which considered a marker for diabetic control over the past 3 months) between PDR, non-PDR and control groups with $\mathrm{p}$ value (0.299). While, A study done by Yun ${ }^{(8)}$ on association between diabetic retinopathy (DR) and HbAlc concluded that DR was significantly more in patients having higher levels of HbA1C, which is in disagreement with our study.Another study conducted by Lind et $\boldsymbol{a l} .{ }^{(9)}$, showed that risk of retinopathy and nephropathy did not differ at HbA1C levels lower than $6.5 \%$, but increased for severe hyperglycaemia compared to HbA1C levels of 6.5-6.9\%. The risk for severe complications mainly occurred at HbA1C levels higher than $8.6 \%$, but for milder complications was increased at $\mathrm{HbA} 1 \mathrm{C}$ levels higher than 7.0\%.In our study we found $\mathrm{HbA} 1 \mathrm{Camong}$ the sample with mean value $=6.9$ ranged from 5.1 to 14 , which means that we had only 4 cases which exceeded 8.6 who were more susceptible to develop severe diabetic complications.

In our study there was no statistically significant difference in creatinine level among PDR, non-PDR, and control groups with $\mathrm{p}$ value $(0.128)$. In our study we excluded the patients with high creatinine level who were suspicious for nephropathy together with screening of protein in urine by simple dip stick method. Hsieh et $\boldsymbol{a l}{ }^{(\mathbf{1 0})}$ studied the association of abnormal renal profiles and PDR and diabetic macular edema in an Asian population with type 2 diabetes. They found that abnormal renal profiles at baseline including high serum creatinine level $(\mathrm{P}<.001)$, low estimated glomerular filtration rate and high urinary albumin $(\mathrm{P}=0.01)$ were associated with the development of PDR in patients with type 2 diabetes. 
Regarding thrombospondin-1 level in serum, our study showed a moderately significant difference among PDR $(1349 \mathrm{pg} / \mathrm{ml} \pm 722.5)$, nonPDR $(1659 \mathrm{pg} / \mathrm{ml}) \&$ control $(1994 \mathrm{pg} / \mathrm{ml})$ groups with (P value: 0.007). In addition, thrombospondin-1 level in serum showed a significant decrease in level in PDR group (1349pg/ml \pm 603.4$)$ compared to control group $(1994 \mathrm{pg} / \mathrm{ml} \pm 470.1)$ with (P value: 0.005$)$. This indicates that thrombospondin-1 level decreases with progression of retinopathy from the non-proliferative stage to the proliferative stage with occurrence of angiogenesis and advancement of inflammation.

ROC curve analysis for serum TSP-1 for

PDR versus control group showed that the area under the curve (AUC) is 0.242 with $\mathbf{9 5 \%}$

Confidence Interval (CI): (0.085-0.398) and the

best cut off point of miRNA-27b is (1.95) with sensitivity (27.8\%) and specificity was (30\%). The

$\mathrm{P}$ value is moderately significant $(0.007)$. this demonstrates that TSP-1 can act as a non-invasive predictor for transformation from non-retinopathy stage to PDR stage.

A study conducted by Wang et al. (11) concluded that in patients with PDR compared to non-diabetic control subjects, the decrease in the TSP-1 level in vitreous fluid samples may play a role in shifting the angiogenic balance and contributing to the pathogenesis of diabetic retinopathy.

Another recent study conducted by Sorenson et $\boldsymbol{a l} .{ }^{(\mathbf{1 2})}$ on TSP1-deficient mice demonstrated more advanced stages of proliferative diabetic retinopathy with a 4-fold increase in cellular capillaries and increased fibronectin.Lack of TSP-1 expression is accompanied by VEGF high expression and reduction of TGF-B (Transforming growth factor b). Lack of TGF-B can cause immunological diseases, inflammation, growth diseasesand wound healing reduction. High expression of VEGF leads to excessive proliferation of vessel endothelial cells ${ }^{(13)}$. Another earlier study performed by Sheibani $\boldsymbol{e t}$ al. ${ }^{(14)}$ who designed it to examine the presence of TSP1 in ocular samples and to determine whether its production is altered in diabetes.

Western blot analysis to detect TSP1in vitreous samples prepared from normal human and rat eyes showed that intact TSP1 was detected in aqueous humor samples prepared from normal rat and bovine eyes. In contrast, TSP1 was virtually absent in vitreous and aqueous humor samples prepared from diabetic rat eyes.

Furthermore, production of TSP1 by microvascular endothelial cells in culture was sensitive to high concentrations of glucose. Retinal blood vessels appeared non-uniform and dilated in diabetic animals when compared to control animals, these results demonstrate that TSP1 is present in aqueous humor and vitreous of normal rat eyes and are dramatically reduced in diabetes. Thus, TSP1 may play a role in ocular vascular homeostasis and its absence may contribute to vascular dysfunctions associated with diabetes.Contrary to the results of our study,Cadena et al ${ }^{(\mathbf{1 5})}$ found that TSP1 profile seen in the NPDR subjects changed significantly (lower levels) when compared to PDR subjects $(\mathrm{P}<0.002)$ and was even significantly different (higher) from that one seen in control subjects (normal human subjects) $(\mathrm{P}<0.002)$. On Westernblotting analysis, Connective Tissue Growth Factor (CTGF) and TSP-1 in plasma and in vitreous humor showed evidence of proteolytic fragmentation, a phenomenon that has been associated with potential promotion of angiogenesis and fibrosis.

There are potential mechanisms through which miRNA directly target signaling molecules that are related to pathological pathways of diabetic retinopathy, such as mitogen-activated protein kinase (MAPK) family, matrix metallopeptidases (MMPs), integrin and hypoxia that induced neovascularization mechanism. Further investigations will be required to gain a better understanding of the regulatory functions of micro RNAs in diabetic retinopathy ${ }^{(16)}$.

In our study, quantitative real-time polymerase chain reaction (PCR) was used to assess the expression of plasma miRNA-27b as the expression levels was calculated using the equation $2^{-\Delta \Delta \mathrm{Ct}}$, we found a highly significant difference in miRNA-27b expression among PDR, non-PDR \& control groups (P value: 0.001).Moreover, when performing multiple statistical comparisons between groups, our study showed a moderately significant increase in miRNA-27b expression in PDR group compared to control group (P value: 0.01), and a near significant increase in miRNA-27b expression in PDR group compared to non-PDR group ( $\mathrm{P}$ value: $0.08)$. On the other side, there was no significant difference in miRNA-27b expression between PDR and control groups (P value: 0.11).

To find out whether plasma levels miRNA-27b could be used as potential diagnostic biomarker for diabetic retinopathy, ROC curve analysis of miRNA027b for PDR versus control group was performed and the area under the curve (AUC) is 0.889 with $\mathbf{9 5 \%}$ Confidence Interval (CI): (0.744-1.0) and the best cut off point of miRNA-27b is (1.95) with sensitivity (88.9\%) and specificity was (100\%). The P value is highly significant $(<0.001)$. This means that miRNA$27 \mathrm{~b}$ has the ability to differentiate between the PDR and control group and could be considered a noninvasive biomarker for diagnosis of diabetic retinopathy.

In agreement with our study, Zampetaki $\boldsymbol{e t}$ $\boldsymbol{a l} .{ }^{(5)}$ found that both miR-27b, miR-320a were significantly and independently associated with new onset of retinopathy in type 1 diabetes (T1D) and 
theirserum expressions were significantly increased with progression of retinopathy ( $p$ value 0.012 ) .

Tang et $\boldsymbol{a l} .{ }^{\left({ }^{(17)} \text { conducted astudy }\right.}$ to investigate whether microRNA-27a (miRNA27a) is associated with the pathogenesis of diabetic retinopathy in retinal pigment epithelial (RPE) cells treated with high glucose andresults of the study suggested that miRNA-27a protects RPE cells subjected to high glucose via inhibiting inflammation and apoptosis through targeting TLR4 (toll like receptor-4).

A study by Liu et al. ${ }^{(18)}$ aimed to explore the potential functional role of microRNA (miR)-27b-3p in lipid and glucose metabolism in T2DM.The study wasconducted on insulin-resistant cell model using quantitative real-time polymerase chain reaction (qRT-PCR). The results showed that the expression levels of miR-27b-3p in the cell model were significantly increased compared to the control group $(\mathrm{P}<0.05)$. The results indicated that miR-27b-3p might play significant roles in the function and metabolism of T2DM.Li et al. $^{(\mathbf{1 9})}$ found significant increase of miR-130a, miR-27b and miR-210 expression in the serum samples of atherosclerosis patients. They concluded that serum levels of miR130a, miR-27b and miR-210 might serve as potential biomarkers for early stage atherosclerosis.

In our study, a correlation analysis had done between plasma expression of miR-27b and laboratory parameters (total cholesterol \& triglycerides) within PDR group, the correlation analysis showed no statistical significance with ( $\mathrm{p}$ values $=0.5$ and 0.9 respectively).

In the current study, the statistical results showed that there was no significant correlation between miRNA-27b expression and TSP-1 level in serum in the PDR group (P value: 0.63 ), or the nonPDR group (P value: 0.79).Another study done by Wang et al. ${ }^{(\mathbf{2 0})}$ concluded that the microRNA miR$27 \mathrm{~b}$ over expression rescues impaired bone marrowderived angiogenic cell (BMAC) function via TSP-1 suppression, semaphorin $6 \mathrm{~A}$ expression in vitro and in vivo in type 2 diabetic mice.Elevated thrombospondin-1 (TSP-1) protein in BMACs was suppressed on miR-27b mimic transfection. Inhibition of miR-27b in BMACs reduced angiogenesis, until now, there are no other studies that tested the correlation between miRNA-27b expression in plasma and level of TSP-1 in serum of patients with different types of diabetic retinopathy.

Moreover, our study showed no significant correlation between miRNA-27b expression and other clinical and laboratory parameters with $(\mathrm{P}$ value $>0.05)$. So far, there are few studies aimed at understanding the dysregulatedmiRNAs in DR. The majority used retinal tissues of various animal models or endothelial cells exposed to high glucose conditions in vitro. Very few studies have used clinical samples or complementary clinical and basic science approaches, as Zampetaki et $\boldsymbol{a l} .{ }^{(5)}$ did. The effects of clinical, pharmacologic, and diabetes device-related interventions on miRNA profiles and their relationships to clinical endpoints are of great interest.

\section{CONCLUSION}

Micro RNA-27b showed a highly significant difference (increase) among PDR compared to nonPDR \& control groups (P value: 0.001) and showed a moderately significant increase in expression in PDR group compared to control group ( $\mathrm{P}$ value: 0.01).This significant increase in microRNA between PDR group and control group has the potentiality of being a biomarker of diagnosis of PDR). As miRNA-27b expression in PDR versus control group showed AUC $=\mathbf{0 . 8 8 9}$ with $\mathbf{9 5 \%}$ CI: (0.744-1.0). The best cut off point of miRNA-27b was (1.95) with sensitivity $(88.9 \%)$ and specificity $(100 \%)$. The $P$ value $<0.001$ (highly significant). This means that miRNA-27b has the ability to differentiate between the PDR and non-retinopathy (control) group and could be considered a noninvasive biomarker.

Serum thrombospondin-1 level (TSP-1) showed a moderately significant difference among PDR, non-PDR \& control groups (P value: 0.007 ) and showed a moderately significant decrease in level in PDR group compared to control group (P value: 0.005 ) showing $\mathbf{A U C}=\mathbf{0 . 2 4 2}$ with $\mathbf{9 5 \%} \mathrm{CI}$ (0.085-0.398). The best cut off point of miRNA27b (1.95) with sensitivity $(27.8 \%)$ and specificity $(30 \%)$. The $P$ value $=0.007$ (moderately significant). From these results, TSP-1 can act as a predictor for transformation of non-PDR to PDR.

\section{RECOMMENDATIONS}

1. We recommendto study miRNAs in other macro and microvascular complications of DM

2. As miRNAs themselves may be therapeutic targets or even therapeutic agents (as anti-miRNAs), further studies will help in identifying and assessing their therapeutic potential for the treatment of retinopathy in individuals with diabetes.In vivo research must be performed to prove the protective effects, safety, and efficiency of miRNA-based therapy

3. Correlations of the studied miRNAs with more laboratory markers.

4. Studying miRNA-27b in a various ophthalmological diseases and in different stages.

5. It would also be of interest to see small RNAsequencing analyses from such trials and to follow up these (or other identified) miRNAs in longitudinal studies to determine their predictive value for DR progression and responses to treatments.

\section{REFERENCES}


1. Neupane S, Dubey RK, Gautam Net al. (2016): Association between serum uric acid, urinary albumin excretion, and glycated hemoglobin in Type 2 diabetic patient. Niger Med J., 57(2): 119-123.

2. ADA (2018): Classification and Diagnosis of Diabetes: Standards of Medical Care in Diabetes. Diabetes Care, 41(1):13-27.

3. Wang W, Lo AC (2018): Diabetic Retinopathy: Pathophysiology and Treatments.Int J Mol Sci., 19(6): 1816-22.

4. Barutta F, Bellini S, Mastrocola Ret al. (2018): MicroRNA and Microvascular Complications of DiabetesInt.https://www.ncbi.nlm.nih.gov/pubmed/2 9707000

5. Zampetaki A, Willeit P, Burr S (2016). Angiogenic microRNAs linked to incidence and progression of diabetic retinopathy in type 1 diabetes.Diabetes, 65(1):216-27.

6. Agroiya P, Philip R, Saran Set al. (2013): Association of serum lipids with diabetic retinopathy in type 2 diabetes Indian J EndocrinolMetab., 17(1): 335-337.

7. Klein BE, Myers CE, Howard KPet al. (2015): Serum Lipids and Proliferative Diabetic Retinopathy and Macular Edema in Persons with Long-term Type 1 Diabetes Mellitus. The Wisconsin Epidemiologic Study of Diabetic Retinopathy. JAMA Ophthalmol.,133(5):503-510.

8. Yun WJ (2010): Relationship between Glycemic Control and Diabetic Retinopathy. J Korean Geriatr Soc., 14(4):234-41.

9. Lind M, Pivodic A, Svensson AM et al. (2019): $\mathrm{HbA}_{1 \mathrm{c}}$ level as a risk factor for retinopathy and nephropathy in children and adults with type 1 diabetes.https://www.ncbi.nlm.nih.gov/pubmed/3146 2492

10. Hsieh YT, Tsai MJ, Tu STet al. (2018): Association of Abnormal Renal Profiles and Proliferative Diabetic Retinopathy and Diabetic Macular Edema in an Asian Population With Type 2 Diabetes.JAMA Ophthalmol., 136(1):68-74.

11. Wang S, Gottlieb JL, Sorenson CMet al. (2009): Modulation of thrombospondin 1 and pigment epithelium-derived factor levels in vitreous fluid of patients with diabetes. Archives of Ophthalmology, 127(4): 507-513.

12. Sorenson CM, Wang S, Gendron Ret al. (2013): Thrombospondin-1 Deficiency Exacerbates the Pathogenesis of Diabetic Retinopathy. Journal of Diabetes \&Metabolism, 12:12-17.

13. Alizadeh S, Beige ZB, Poor Heravi SAet al. (2019): Study of Serum Thrombospondin-1 Level in Diabetic Patients with Diabetic Foot Ulcer. J MolPatholBiochem., 1(10):102-107.

14. Sheibani N, Sorenson CM, Cornelius LAet al. (2000): Thrombospondin-1, a natural inhibitor of angiogenesis, is present in vitreous and aqueous humor and is modulated by hyperglycemia. BiochemBiophys Res Commun., 267(1):257-61.

15. Cadena RA, Rico MC, Carpio-Cano FDet al. (2011):Thrombospondin-1 (TSP1), Transforming Growth Factor-Beta (TGFb) and Connective Tissue Growth Factor (CTGF) are involved in the Pathophysiology of Diabetic Retinopathy. American Society of Hematology, 118 (21): 3275-9.

16. Ye EA, Steinle J (2017): Regulatory role of microRNA on inflammatory responses of diabetic retinopathy,NeuralRegen Res., 12(4): 580-581.

17. Tang X, Dai Y, Wang Xet al.(2018). MicroRNA27a protects retinal pigmentepithelial cells under high glucose conditions by targeting TLR4. Experimental and therapeuticmedicine, 16(1): 452-458.

18. Liu Y, Wang G, Yang X (2018): MicroRNA-27b-3p regulates function and metabolism in insulin resistance cells by inhibiting receptor tyrosine kinaselike orphan receptor 1. The Plant Cell, 24 (11): 43334345.

19. LiT, CaoH, ZhuangJet al.(2010): Identification of miR-130a, miR-27b and miR-210 as serum biomarkers for atherosclerosis obliterans. International Journal of Clinical Chemistry, 412(12):66-70.

20. Wang L, Yang Y, Hong B et al.(2013): Advances in the role of microRNAs in lipid metabolism-related anti-atherosclerotic drug discovery. Expert Opin Drug Discov., 8: 977-990. 